\title{
STUDY ON FORCE MECHANISM OF CABLE-TRUSS FRAME AND JUMPED LAYOUT OF ANNULAR CROSSED CABLE-TRUSS STRUCTURE
}

\author{
Jian $\mathrm{Lu}^{1}$, Xiong-Yan Li ${ }^{1,}{ }^{*}$, Su-Duo Xue ${ }^{1}$, Ren-Jie Liu ${ }^{2}$ and Majid Dezhkam ${ }^{1}$ \\ ${ }^{I}$ College of Civil and Architecture Engineering, Beijing University of Technology, China \\ ${ }^{2}$ Civil Engineering College Institute, Yantai University, Yantai, Shandong 264000, China \\ *(Corresponding author: E-mail: xiongy2006@126.com)
}

\section{A B S T RA C T}

A new type of cable-strut tension structure named Annular Crossed Cable-truss Structure(ACCTS) comprises a series of planar cable-truss frames crossed each other. To investigate the force mechanism of ACCTS, a cable-truss frame model with 2-bar and 6-cable has been developed, and its initial stiffness formula has been derived as well. The model is further simplified to make it is upper and lower vector heights equal, and then the initial stiffness formula and the critical slack load formula are further deduced. Based on ANSYS software and cable-truss frame with a span of $60 \mathrm{~m}$, the influences of the number of struts and position of jumped layout on the cable-truss frame are studied. According to the former $60 \mathrm{~m}$ span cabletruss frame's research results, the jumped layout of ACCTS with a span of $100 \mathrm{~m}$ is studied. The static and dynamic performances of two schemes, the optimal jumped layout scheme and the original scheme, are systematically studied. It is shown that the number of struts would be about $6 \sim 8$ for the planar cable-truss frame and the optimal order of jumped layout is strut $6-7 \rightarrow$ strut $4-5 \rightarrow$ strut 2-3. The optimal order of jumped layout of ACCTS agrees with that of the cable-truss frame, verifying the feasibility of conclusions. In the condition of no variation in the original structure's static and dynamic performance, the optimal scheme of the jumped layout will lower the steel consumption and enhance the buckling loads Moreover, it also simplifies structure for easy construction.

\section{A R T I C L E H I S T O R Y}

$\begin{array}{ll}\text { Received: } & \text { 16 May 2020 } \\ \text { Revised: } & \text { 8 March 2021 } \\ \text { Accepted: } & \text { 13 March 2021 }\end{array}$

\section{K E Y W O R D S}

Planar cable-truss frame

Annular Crossed Cable-truss

structure (ACCTS);

Force mechanism;

Jumped layout;

Static and dynamic performance

\section{Introduction}

Cable-strut tension structure [1-2], an essential part of large-span spatial structures, is well known in the construction industry for its lightweight, beautiful appearance, fast construction speed, considerable spanning ability, and so on. Furthermore, cable-truss tension structure is one of the most competitive structure types in cable-truss tension structures [3-4]. Cable-truss tension structure refers to the integral tension structure formed by the same kind of planar cable-truss frames according to certain layout principles. This kind of structure's common point is that the integral structure can be divided into the same kind of planar cable-truss frames. Meanwhile, planar cable-truss frames share the same characteristics, such as lightweight, high stiffness, sizeable spanning ability, and simple construction. At present, cable-truss tension structures mostly include two genres: Spoke Cable-truss Structure [5] and Annular Crossed Cable-truss Structure (ACCTS) [6-8].

Spoke Cable-truss Structure cases involve Foshan Stadium, Shenzhen Baoan Stadium, Yueqing Stadium [5], Busan Stadium in South Korea [9], and so on. But ACCTS is still at the stages of theoretical and experimental research, and there are no any project cases in the world. So, there are still lots of unfinished studies about ACCTS, including how to solve self-stress modes, how to construct, how to simplify structure, and so on.

ACCTS as a novel cable-truss tension structure is composed of a series of planar cable-truss frames interwoven with each other [6-7]. It shares two load transfer paths that strengthen the structure's anti-collapse capacity [6,10-11]. The form of ACCTS results in its strong anti-collapse capacity; however, its form also leads to the difficulty of erection. In the further studies, it is found that although ACCTS has a strong anti-collapse capacity, its construction forming is too difficult. With the increase of ACCTS's span, the strut number and length will be enlarged, and serious collision and winding of struts occur during construction due to ACCTS formed by a series of planar cable-truss frames interwoven with each other, which cause many difficulties in construction. If there is a way to reduce struts number, it will simplify its construction process, and the structural self-weight will be reduced as well. Thus it is necessary to evaluate the effect on struts being removed from ACCTS

In the paper, a cable-truss frame finite element model with a span of $60 \mathrm{~m}$ is established, and the influences of the number of struts and position of jumped layout on the cable-truss frame are studied. And then the jumped layout for ACCTS is studied. Finally, based on the optimal scheme of jumped layout, the optimal scheme's static and dynamic performance are studied. Research methods and results provide simplified methods and theoretical basis for the construction of ACCTS and provide a new method to simplify cable-truss frame and ACCTS.

\subsection{Theory analysis of planar cable-truss frame}

Take the 2-bar and 6-cable planar cable-truss frame in Fig.1 as an example, and study its force mechanism under concentrated load. Assuming that:

(1) The two terminals of the cable-truss frame are rigid, the same below;

(2) The angles between cables and struts are unchanged in a small elastic range;

(3) The cables and struts are not slipped at nodes.

In Fig. 1, the initial pre-stresses of upper and lower chord cables of cable truss frames are $T_{1}$ and $T_{2}$, respectively. The angles between $T_{1} \sim T_{2}$ and the axis are the $\theta_{1}$ and $\theta_{2}$. Under load $\mathrm{P}$, the vertical deformations of two terminals of the strut are $\delta_{1}$ and $\delta_{2}$. Meanwhile, the variation of internal forces of upper and lower cables are the $\triangle T_{1}$ and $\triangle T_{2}$. The modulus and section area of cable is $E_{c}$ and $A_{c}$, respectively. The modulus and section area of the strut are $E_{s}$ and $A_{s}$, respectively.

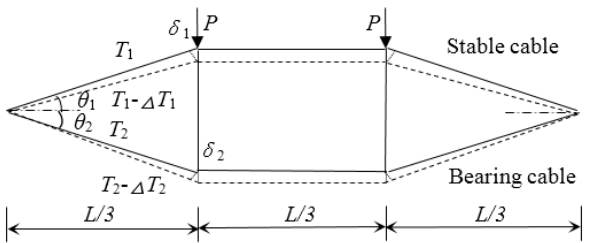

Fig. 1 Force diagram of planar cable-truss frame

Under load $\mathrm{P}$, the vertical deformations of two terminals of strut are $\delta_{1}$ and $\delta_{2}$, the length variations of upper and lower chord cables are as follows:

$\left\{\begin{array}{l}\Delta l_{1}=\delta_{1} \sin \theta_{1} \\ \Delta l_{2}=\delta_{2} \sin \theta_{2}\end{array}\right.$

According to the length variations of upper and lower chord cables, its variations of cable forces are as follows:

$\left\{\begin{array}{l}\Delta T_{1}=E_{c} A_{c} \frac{3 \delta_{1}}{L} \sin \theta_{1} \cos \theta_{1} \\ \Delta T_{2}=E_{c} A_{c} \frac{3 \delta_{2}}{L} \sin \theta_{2} \cos \theta_{2}\end{array}\right.$

The internal forces of upper and lower chord cables are: 
$\left\{\begin{array}{l}\overline{T_{1}}=T_{1}-\Delta T_{1}=T_{1}-E_{c} A_{c} \frac{3 \delta_{1}}{L} \sin \theta_{1} \cos \theta_{1} \\ \overline{T_{2}}=T_{2}+\Delta T_{2}=T_{2}+E_{c} A_{c} \frac{3 \delta_{2}}{L} \sin \theta_{2} \cos \theta_{2}\end{array}\right.$

From the equilibrium relation of upper and lower nodes of struts, it can be gained as follows:

$$
P+\bar{T}_{1} \sin \theta_{1}=\overline{T_{2}} \sin \theta_{2}
$$

Sustitute Eq.(3) into Eq.(4), the relation between external loads and structural displacements are as follows:

$$
\begin{aligned}
& P=\left(T_{2} \sin \theta_{2}-T_{1} \sin \theta_{1}\right) \\
& +E_{c} A_{c} \frac{3}{L}\left(\delta_{1} \sin ^{2} \theta_{1} \cos \theta_{1}+\delta_{2} \sin ^{2} \theta_{2} \cos \theta_{2}\right)
\end{aligned}
$$

It can be gained according to the forced relation of struts:

$$
\frac{\delta_{1}-\delta_{2}}{\left(\tan \theta_{1}+\tan \theta_{2}\right) L / 3}=\frac{\Delta T_{2} \sin \theta_{2}}{E_{s} A_{s}}
$$

Combining Eq.(5) and Eq.(6), it can be gained as follows:

$P=\left(T_{2} \sin \theta_{2}-T_{1} \sin \theta_{1}\right)+$

$\frac{3 E_{c} A_{c} \delta_{1}}{L} \sin ^{2} \theta_{1} \cos \theta_{1}+\frac{3 E_{c} A_{c}}{L} \sin ^{2} \theta_{2} \cos \theta_{2} \times$

$$
\frac{\delta_{1} E_{s} A_{s}}{E_{s} A_{s}+E_{c} A_{c} \sin ^{2} \theta_{2} \cos \theta_{2}\left(\tan \theta_{1}+\tan \theta_{2}\right)}
$$

When the angles between upper and lower chord cables and center axis are the same $\left(\theta_{1}=\theta_{2}\right)$, the Eq.(7) can be simplified as follows:

$$
P=\frac{3 E_{c} A_{c} \delta_{1}}{L} \sin ^{2} \theta_{1} \cos \theta_{1}\left(1+\frac{E_{s} A_{s}}{E_{s} A_{s}+2 E_{c} A_{c} \sin ^{3} \theta_{1}}\right)
$$

When the stable cables (upper chord cables) are slack under external laods, use the above analysis method and the slack stiffness of cable-truss frame can be obtained as follows:

$$
K=\frac{3 E_{c} A_{c}}{L} \sin ^{2} \theta_{1} \cos \theta_{1} \frac{E_{s} A_{s}}{E_{s} A_{s}+2 E_{c} A_{c} \sin ^{3} \theta_{1}}
$$

From Eq.(3) and Eq.(4), when upper chord cables are slack, the critical slack load of the cable-truss frame can be gained as follows:

$$
P_{c r}=T_{1} \sin \theta_{1}\left(1+\frac{E_{s} A_{s}}{E_{s} A_{s}+2 E_{c} A_{c} \sin ^{3} \theta_{1}}\right)
$$

Eq.(8) is the initial stiffness equation of the cable-truss frame, and it can be seen from Eq.(8) that the pre-stresses have no effects on the initial stiffness of the cable-truss frame. Eq.(9) is the slack stiffness equation when upper chord cables are slack. From Eq.(8) and Eq.(9), it can be known that the initial stiffness and slack stiffness have mainly consisted of structural material and shape parameter $\sin ^{2} \theta_{1} \cos \theta_{1}$ of the cable-truss frame. It can be seen from Eq.(10) that the critical slack load is linear with the initial pre-stress of a cable when the upper chord cable is slack.

\subsection{FEM analysis of cable-truss frame}

Take the example in Ref. [12] as a research objective. The planar cable-truss frame is shown in Fig. 2. Element 2-3 and element 4-5 are the struts, and the others are the cables. The material parameters of cable and strut are shown in Table 1.

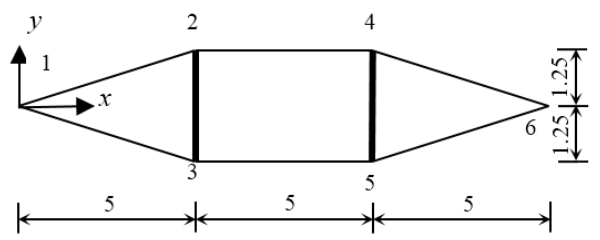

Fig. 2 Schematic diagram of planar cable-truss frame Unit:m

Table 1

Material parameter of cable-strut frame

\begin{tabular}{cccc}
\hline Material & Section area $/ \mathrm{mm}^{2}$ & Elastic modulus/MPa & Poisson's ratio \\
\hline Cable & 28.2743 & $1.80 \times 10^{5}$ & 0.3 \\
Strut & 7.0686 & $2.06 \times 10^{5}$ & 0.3 \\
\hline
\end{tabular}

When initial pre-stresses are $2.5 \mathrm{kN}, 5 \mathrm{kN}, 7.5 \mathrm{kN}, 10 \mathrm{kN}, 12.5 \mathrm{kN}, 15 \mathrm{kN}$, respectively, the comparsion results between Eq.(10) and FEM method are shown in Fig. 3. The relation of load-displacement of cable-truss frame under different initial pre-stresses is shown in Fig. 4.

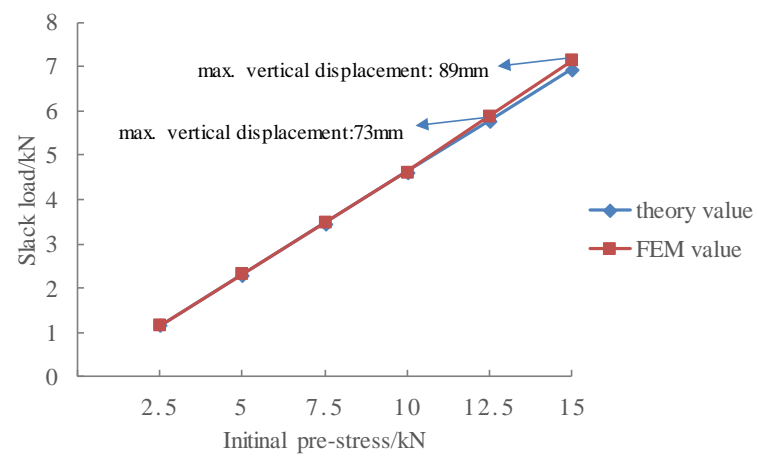

Fig. 3 Critical slack loads $P_{\mathrm{cr}}$

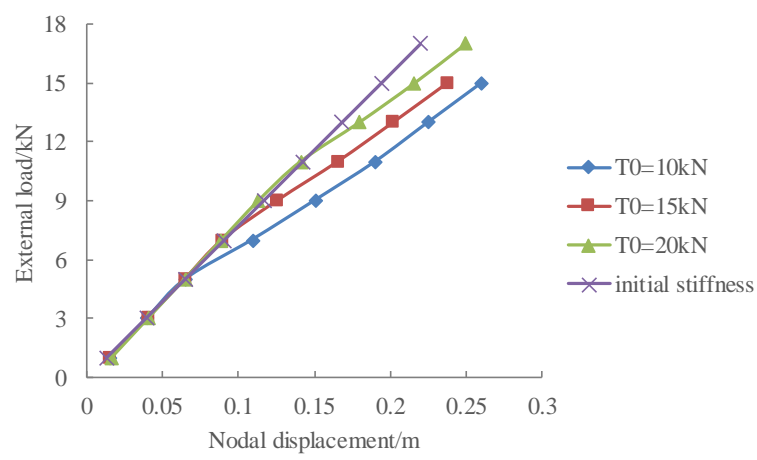

Fig. 4 Load-displacement curve of cable-truss frame

From Fig. 3, it can be seen that the theoretical values are linear with the FEM values, which verifies that the theory equations are correct. When the pre-stresses are higher, the FEM values are larger than the theoretical values. The reason is that the larger the critical slack loads are, the larger deformations of the cabletruss frame are under critical slack loads, shown in Fig. 3. 《Technical Specification for Cable Structure $》$ JGJ257-2012 [13] specifies that the maximum allowable displacement is $[\sigma]=l / 200=7.5 \mathrm{~mm}(l$ is the span of the cabletruss frame.). When the $\mathrm{T}_{0}$ is $15 \mathrm{kN}$, the maximum displacement is $8.9 \mathrm{~mm}$, which does not meet the requirements. So the initial pre-stresses of the cable-truss frame should not be too large.

It can be seen from Fig. 4 that the load-displacement curves of cable-truss frames under different pre-stresses are composed of two sections. The first section is the change law of stiffness when the upper chord cable is not slack, which shows that stiffness variation has no connection with initial pre-stresses and the change law is the same as Eq.(8). When the upper chord cable is not slack, 
the cable-truss frame's load-displacement curve is the same as the initial stiffness curve. The second section is the change law of stiffness when the upper chord cable is slack, which shows that adding the initial pre-stresses of cables can increase the cable-truss frame's critical slack loads.

\section{Study the influences of the position of struts on cable-truss frame}

\subsection{The case is that the position of middle struts is fixed}

Design a cable-truss frame with a span of $60 \mathrm{~m}$ and keep the position of two middle struts fixed. The influences of the number of struts on the cable-truss frame are studied when the number of struts is $2,4,6$, and 8 (the lengths of two sides of middle struts are equally divided by the newly added struts). By Ref. [14], the economic rise-span ratio of stable cable and bearing cable is $1 / 25 \sim 1 / 20$ and $1 / 20 \sim 1 / 15$, respectively. So, the rise-span ratio of stable cable and bearing cable is $1 / 20$. Namely, the vector heights of upper and lower chord cables are all $3 \mathrm{~m}$. Taking model 2 as an example, considering the integral cable-truss frame's reasonable forces, the lengths of struts should satisfy $h_{2}<h_{1}<2 h_{2}$. The four models of the cable-truss frame are shown in Fig.5. The cable forces of middle cable sections for four models are all $300 \mathrm{kN}$, and the material parameters of cable and strut are shown in Table 2.

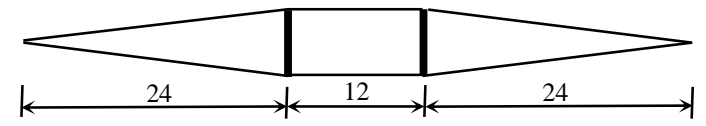

(a) Model $1-2$ struts model

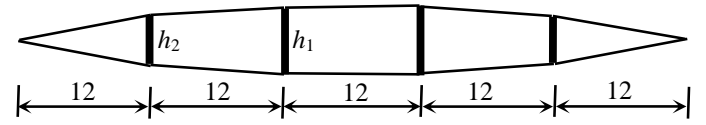

(b) Model $2-4$ struts model

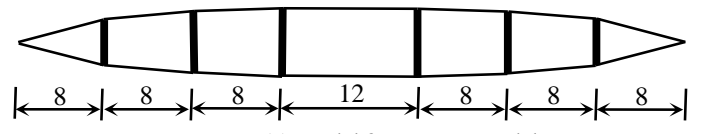

(c) Model 3 - 6 struts model

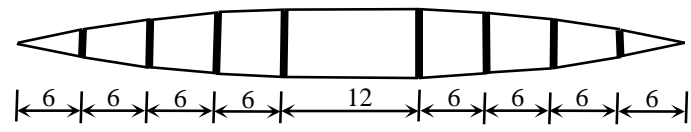

(d) Model $4-8$ struts model

Fig. 5 Four cable-truss frame models when middle struts are fixed Unit: $m$

Table 2

Material parameters of cable and strut

\begin{tabular}{ccccc}
\hline Material & $\begin{array}{c}\text { Cross- } \\
\text { section/mm }\end{array}$ & $\begin{array}{c}\text { Elastic } \\
\text { modulus/MPa }\end{array}$ & $\begin{array}{c}\text { Thermal } \\
\text { expansion } \\
\text { coefficient }\end{array}$ & $\begin{array}{c}\text { Poison's } \\
\text { ratio }\end{array}$ \\
\hline Cable & 731.00 & $1.80 \times 10^{5}$ & $1.2 \times 10^{5}$ & 0.3 \\
Strut & 1414.00 & $2.06 \times 10^{5}$ & $1.2 \times 10^{5}$ & 0.3 \\
\hline
\end{tabular}

Under external loads, the nodal load-displacement curves of four cable-truss frame models with or without self-weight are shown in Figs. 6 7. The first six frequencies are shown in Fig. 8.

From Fig. 6, when the two middle struts are fixed, the cable-truss frame's displacements increase with the increase of the number of struts. When the number of struts is more than 6 , the number of struts on the cable-truss frame's displacements are small. So, it is not that the more struts are, the more advantageous it is to reduce the displacement of the cable-truss frame. The number of struts should be controlled within a specific range. It is suggested that the number of struts should be about $6 \sim 8$ for that kind of cable-truss frame.

From Figs. 6 7, the load-displacement curves of four cable-truss frame models with or without self-weight are identical, showing self-weight has little effects on the cable-truss frame. From Fig. 8, the frequencies of model 1 are the largest, and the frequencies of model 2 and model 3 are close to each other. The vibration modes of the four models are identical (the vibration modes of the cable-truss frame are mainly upper and lower vibration accompanied by local torsion of cable-truss frame), which shows that the number of struts does not change its vibration features.

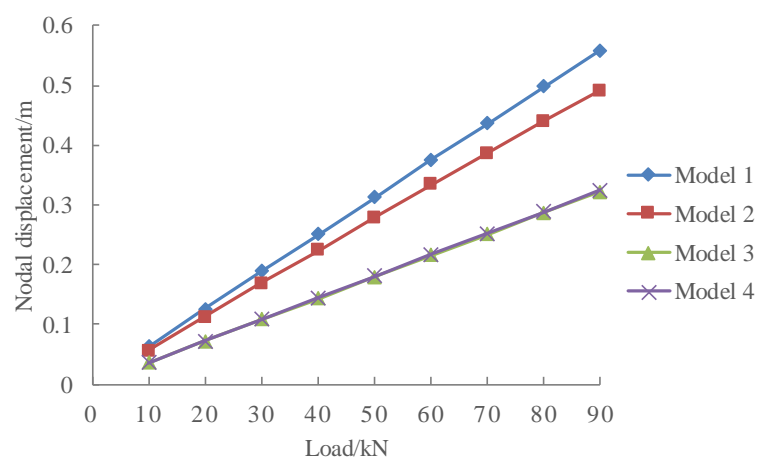

Fig. 6 Nodal load-displacement curves without self-weight

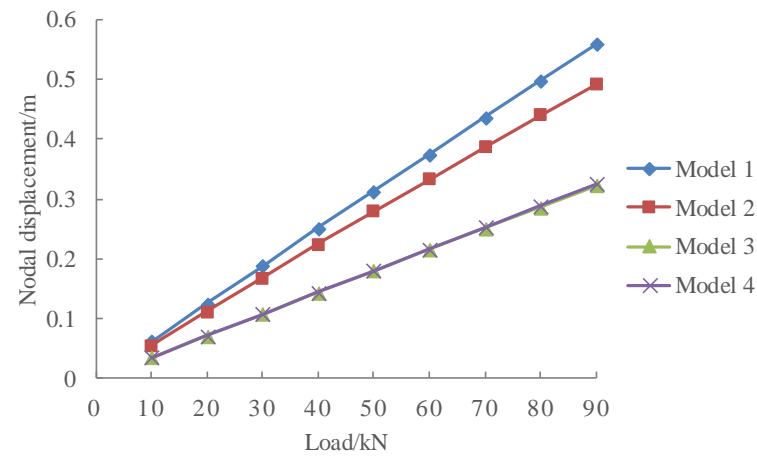

Fig. 7 Nodal load-displacement curves with self-weight

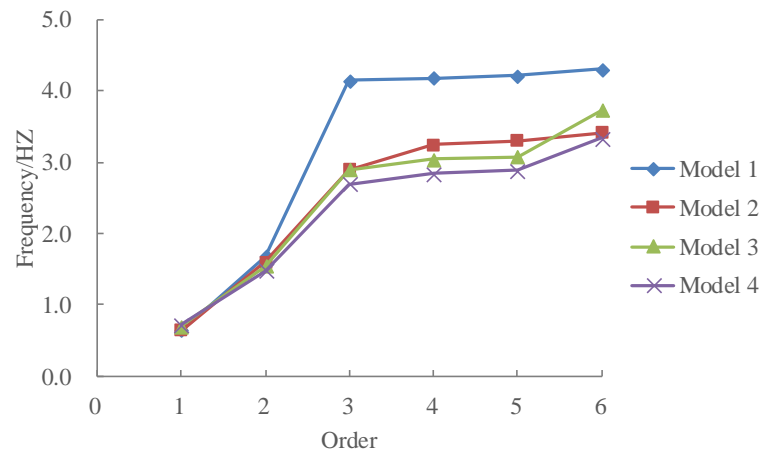

Fig. 8 First sixth frequencies of four models

\subsection{The case is that the position of middle struts is not fixed}

The case that middle struts' position is not fixed refers to taking all struts to equalize the span of the cable-truss frame. When the number of struts is not equal, the distance between every two struts is also different. When the middle struts position is not fixed, the four models of the cable-truss frame are shown in Fig. 9 , and the material parameters are shown in Table 2.

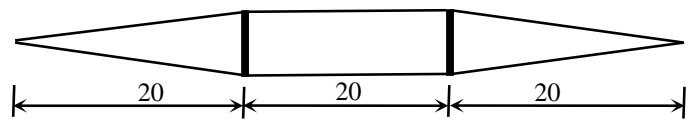

(a) Model $1-2$ struts model

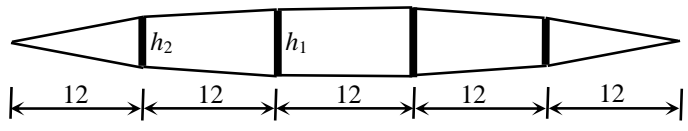

(b) Model $2-4$ struts model

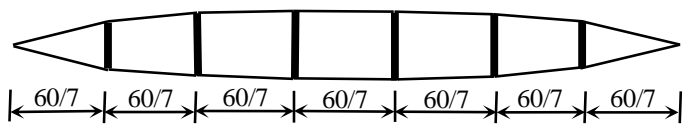

(c) Model 3-6 struts model 


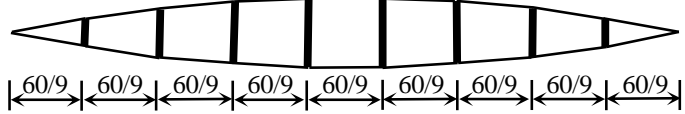

(d) Model 4-8 struts model

Fig. 9 Four cable-truss frame models when middle struts are not fixed Unit: $m$

Under external loads, the nodal load-displacement curves of four cable-truss frame models are shown in Fig. 10, and the first six frequencies are shown in Fig. 11.

From Fig. 10, with the increase of the number of struts, the displacement variations of the four models are not the same. However, when the number of struts is more than 4 , the four models' displacement variations are minimal, and the maximum displacement difference is $18.08 \mathrm{~mm}$. Therefore, when the number of struts exceeds a specific range, it is not apparent to reduce the cable-truss frame's displacement by increasing the number of struts. It suggests that the number of struts should be about 6 8. Moreover, it is known from Fig. 11 that the first six frequencies and vibration modes are identical.

It can be seen from Fig. 10 11 that when the span of the cable-truss frame is fixed, the first-order frequency of the cable-truss frame is lower whether the position of the middle struts is fixed or not, which shows that the cable-truss frame is soft. The external excitation can easily disturb the cable-truss frame. So, planar cable-truss frames are mostly arranged in the form of positive, oblique, or additional linked cables to form spatial cable-truss tension structure in practical engineering to improve the lateral stiffness and integral stability of the cabletruss frame.

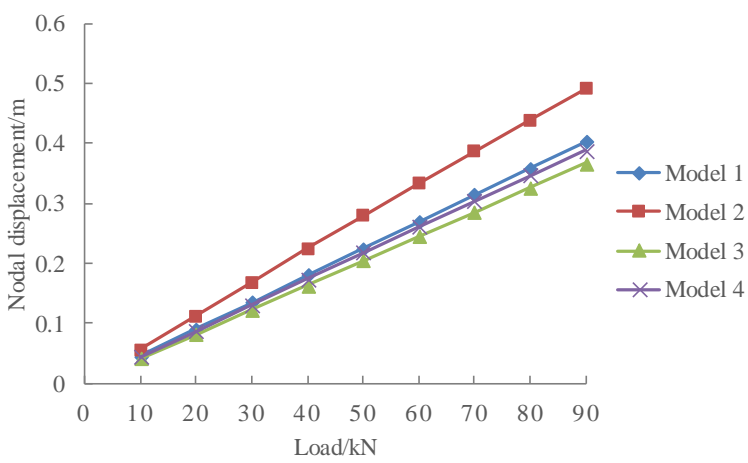

Fig. 10 Load-displacement curves of nodes

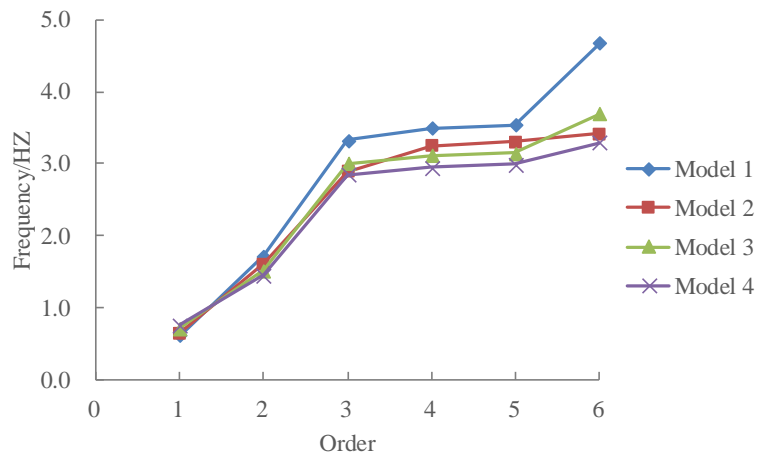

Fig. 11 First 6th frequencies of four models

\section{Study on the effects of jumped layout on cable-truss frame}

Taking model 4 in Section 3.1 as a research objective (shown in Fig. 5d). Jumped layout refers to studying the effects of jumped layout on the cable-truss frame's mechanical behaviors when 2-3, 4-5, 6-7, as well as its symmetrical position, are separately removed (shown in Fig. 13b, Fig. 13c, and Fig. 13d, respectively).

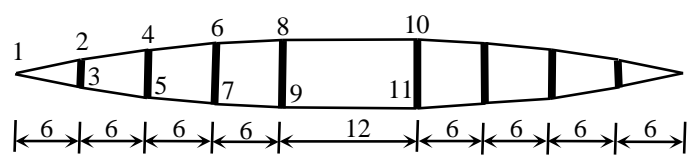

Fig. 12 Model 4 - eight struts model Unit: $m$
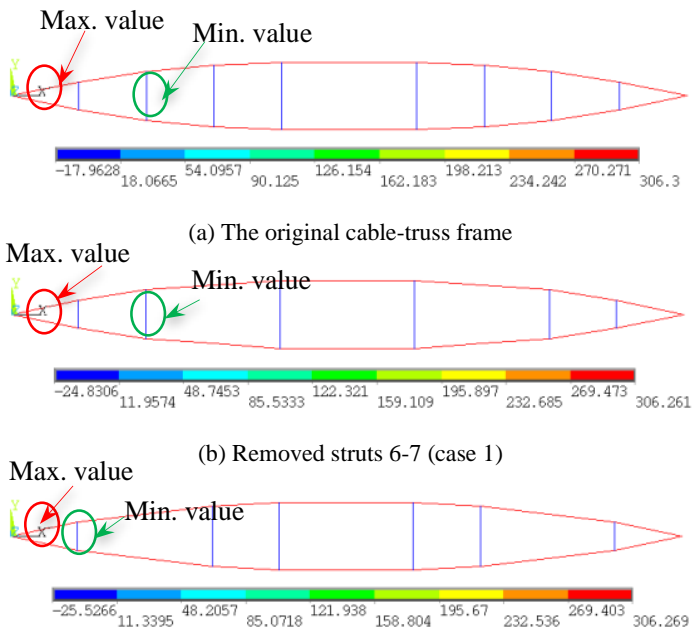

(c) Removed struts 4-5 (case 2)

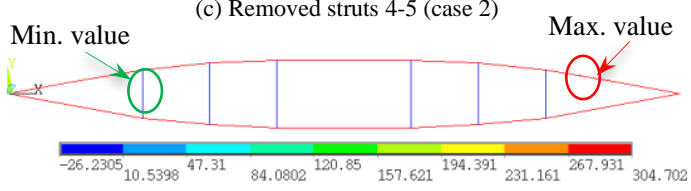

(d) Removed struts 2-3 (case 3)

Fig. 13 Internal force diagrams of cable-truss frame after jumped layout Unit: kN

It can be seen from Fig. 13 that the changes of pre-stress values are small under the pre-stress condition, and the position of maximum pre-stress value does not change. However, the changes of internal forces of struts are large, and the maximum displacement position also changes. From the changes of internal forces and position of cables and struts, the influence of the struts' position on the cable-truss frame is: strut 2-3>strut 4-5>strut 6-7. Therefore, when optimizing the cable-truss frame's struts, the optimal order of jumped layout is: strut 6$7 \rightarrow$ strut $4-5 \rightarrow$ strut $2-3$.

The original cable-truss frame and the upper chord cable 8-10 and lower chord cable 9-11 in case 1 3 are taken to study under different loads. The comparison results are shown in Fig. 14. Meanwhile, the internal forces of strut 2-3 and strut 4-5 in the original cable-truss frame are compared with those of strut 4-5 in case 1, strut 2-3 in case 2 , strut 4-5 in case 3 . The comparison results are shown in Fig. 15. Under different loads, the cable-truss frame's displacements after jumped layout are compared with those of the original cable-truss frame, shown in Fig. 14.

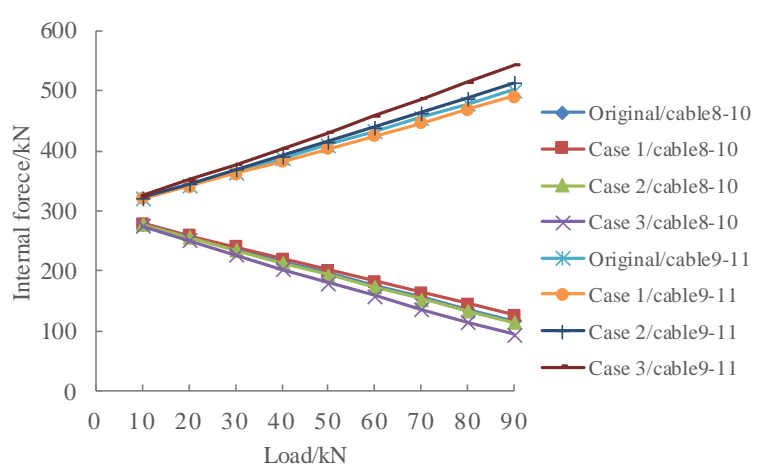

Fig. 14 Draw of cable force under various conditions

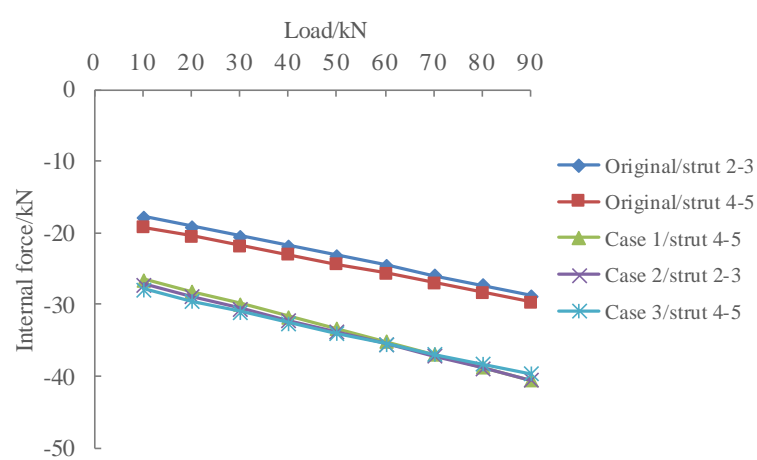

Fig. 15 Draw of internal force of struts under various conditions (In Figs. 14 15, "Original" refers to "the original scheme", the same below.) 


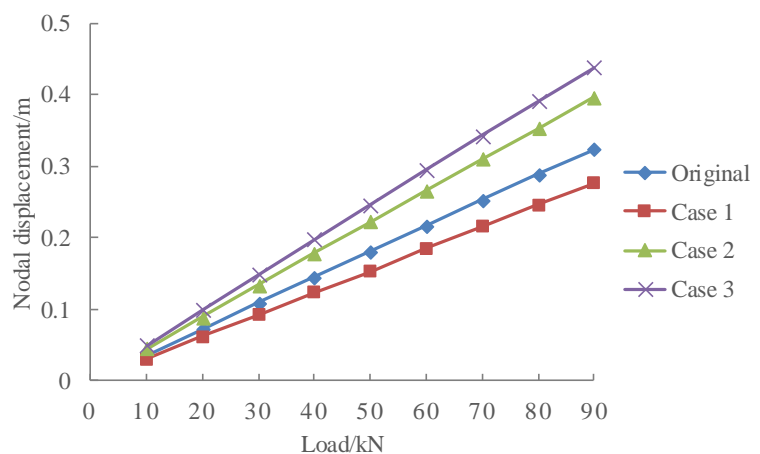

Fig. 16 Load-displacement curves under various conditions

From Fig. 14, although the positions of jumped layout are different, the changes of upper and lower chord cables for all models are small. For the three cases, the cable force in case 3 changes in larger, but it still can be controlled. Namely, the effects of position of jumped layout on cable-truss frame is small. From Fig. 15, it is known that the internal forces of struts in jumped layout model have changed significantly. The maximum internal force occurs at strut 2-3. The maximum internal forces range from $9.381 \sim 11.713 \mathrm{kN}$ under different external loads. So, the cross-section areas of struts should be rechecked after jumped layout. From Fig. 16, the load-displacement curves of jumped layout model and the original model linearly change. Namely, jumped layout does not change the mechanical performance of the cable-truss frame.

Meanwhile, the displacement variation in case $3>$ case $2>$ original model $>$ case 1 . So, when the number of struts is large, there are more redundant struts in the cable-truss frame, which cannot improve structural performance but increase the self-weight, the number of joints, and the difficulty of construction. So, the optimal order of jumped layout is case $1 \rightarrow$ case $2 \rightarrow$ case 3 .

\section{Study on the influence of struts on ACCTS}

In further studies, it is found that although ACCTS has a strong anti-collapse capacity, its construction forming is very difficult. The main reasons are that when the ACCTS's span is large, there are lots of struts and its lengths are longer. A structure is formed by a series of planar cable-truss frames interwoven with each other; serious collision and winding of struts occur during construction, which leads to lots of difficulties in construction. If partial struts of ACCTS can be removed, it can simplify construction, reduce construction difficulty, and structural self-weight. Nevertheless, the influence of jumped layout on ACCTS needs further studies.

Design an ACCTS with a span of $100 \mathrm{~m}$ shown in Fig. 17, which is constituted by 15 planar cable-truss frames interwoven with each other. The size of a single cable-truss frame is shown in Fig. 18. The elastic modulus and density of cable are $1.38 \times 10^{5} \mathrm{MPa}$ and $7.85 \mathrm{~g} / \mathrm{cm}^{3}$, respectively. The elastic modulus and density of the strut are $2.06 \times 10^{5} \mathrm{MPa}$ and $7.85 \mathrm{~g} / \mathrm{cm}^{3}$, respectively. The crosssections of the cable and strut are shown in Table 3 .

\subsection{The influences of the position of jumped layout on ACCTS}

Because the coordinates of the virtual inner ring of ACCTS decide the outer shape, the rise-span ratio of upper and lower chord cables and drainage slope, the vector height of ACCTS is not changed. Namely, the struts in the virtual inner ring are not removed, shown in Fig. 19. The jumped layout positions are located in the inner ring 1 , the inner ring 2 , and the inner ring 3, respectively, corresponding to scheme 1 , scheme 2 , and scheme 3 .

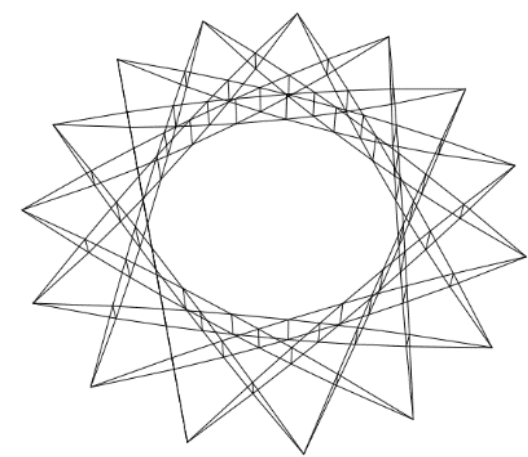

Fig. 17 Perspective of ACCTS

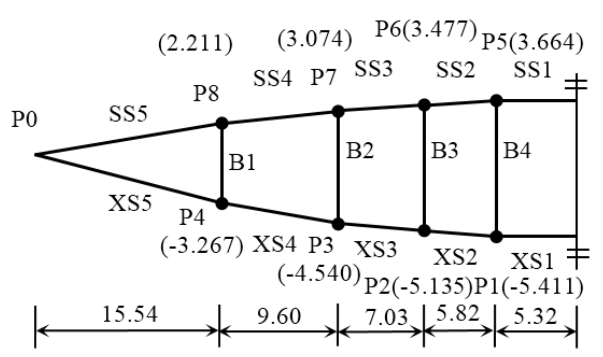

Fig. 18 Half cable-truss frame Unit:m

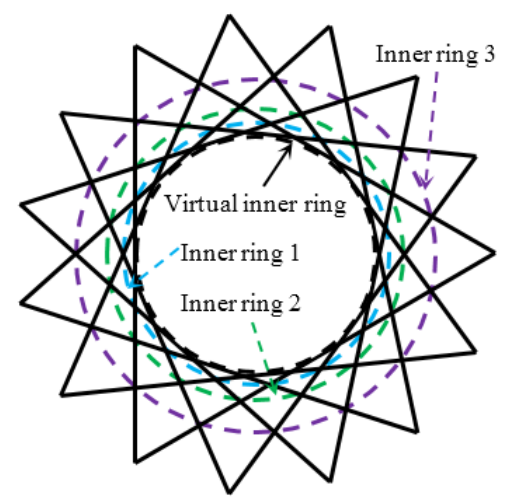

Fig. 19 Plane diagram of jumped layout

\subsubsection{Feasible prestress comparison}

From Table 3, the distribution law and values of feasible pre-stresses are identical among the original scheme and three jumped layout schemes. The internal forces of elements near the position of jumped layout change in larger. The internal force changes of scheme 2 and scheme 3 are more extensive than those of scheme 1 . The force changes of scheme 2 and scheme 3 are dramatically mostly for internal forces of struts. Such as the internal force of strut B3 in scheme two changes from $-18.26 \mathrm{kN}$ to $-32.13 \mathrm{kN}$, and the internal force of strut B2 changes from $-23.62 \mathrm{kN}$ to $-47.68 \mathrm{kN}$, so removed struts has the greatest influence on struts.

Table 3

Pre-stress distribution of all kinds of components of ACCTS Unit: kN

\begin{tabular}{|c|c|c|c|c|c|c|c|c|c|c|c|c|c|c|}
\hline Element number & $\mathrm{XS} 1$ & $\mathrm{XS} 2$ & XS3 & XS4 & XS5 & SS1 & SS2 & SS3 & SS4 & SS5 & B1 & B2 & B3 & B4 \\
\hline $\begin{array}{c}\text { Cross-section } \\
\text { areas } / \mathrm{mm}^{2} \\
\end{array}$ & 1360.9 & 1360.9 & 1360.9 & 1360.9 & 1360.9 & 1360.9 & 1360.9 & 1360.9 & 1360.9 & 1360.9 & 3078.7 & 3078.7 & 3078.7 & 3078.7 \\
\hline Original scheme & 270.86 & 271.26 & 271.96 & 273.36 & 276.84 & 327.23 & 327.39 & 327.68 & 328.39 & 330.38 & -38.23 & -23.62 & -18.26 & -23.32 \\
\hline Scheme 1 & 266.73 & 267.18 & 267.39 & 269.06 & 272.51 & 329.52 & 326.73 & 329.21 & 329.52 & 331.47 & -37.93 & -31.69 & - & -33.07 \\
\hline Scheme 2 & 270.49 & 270.94 & 272.18 & 272.37 & 276.45 & 333.08 & 333.21 & 334.05 & 333.86 & 336.29 & -48.57 & - & -32.13 & -23.48 \\
\hline Scheme 3 & 272.2 & 272.63 & 273.34 & 276.4 & 276.77 & 332.02 & 332.17 & 332.46 & 334.57 & 334.28 & - & -47.68 & -18.43 & -23.53 \\
\hline
\end{tabular}




\subsubsection{The comparison of structural responses under external loads}

Firstly applying loads of $0.6 \mathrm{kN} / \mathrm{m} 2$ to ACCTS, and then transforming the surface loads into the equivalent nodal load $F$, the equivalent nodal loads of all kinds of nodes are calculated $F_{\mathrm{P} 1}=-12.42 \mathrm{kN}, \quad F_{\mathrm{P} 2}=-22.88 \mathrm{kN}, \quad F_{\mathrm{P} 3}=-47.952 \mathrm{kN}$, $F_{\mathrm{P} 4}=-86.571 \mathrm{kN}$, respectively. The structure's total loads $\operatorname{are} \boldsymbol{F}=15^{*}\left[F_{\mathrm{P} 1}, F_{\mathrm{P} 2}, F_{\mathrm{P} 3}, F_{\mathrm{P} 4}\right]$ (The negative sign indicates the downward direction of load). The original scheme's structural responses and three jumped layout schemes under load $\boldsymbol{F}$ are shown in Fig. 20 and Table 4.

It can be seen from Table 4 that the maximum and minimum internal forces of cables change slightly and appear in the same position under load $\boldsymbol{F}$. From the changes of cable forces, scheme 1 is the closest to the original scheme. The maximum and minimum internal forces of struts have changed obviously, and the position of struts has also changed. The internal forces of struts of three jumped layout schemes have changed to a certain extent. The cross-section areas of struts should be rechecked to meet the design requirements after jumped the layout. In the three schemes, the maximum structural displacement position is unchanged, roughly to the three inner rings, but the maximum displacements change considerably. The maximum displacement in scheme 1 is very close to that of original scheme. The maximum displacement of scheme 2 is $-0.489 \mathrm{~m}$, but it still satisfies the allowable deformation value $[\sigma]=0.5 \mathrm{~m}$ in $《$ Technical Specification for Cable Structure 》 JGJ257-2012 [13]. The maximum displacement value in scheme 3 is $-0.679 \mathrm{~m}$, which exceeds allowable value in code. So, the mechanical performance of scheme 1 is similar to that of the original scheme.

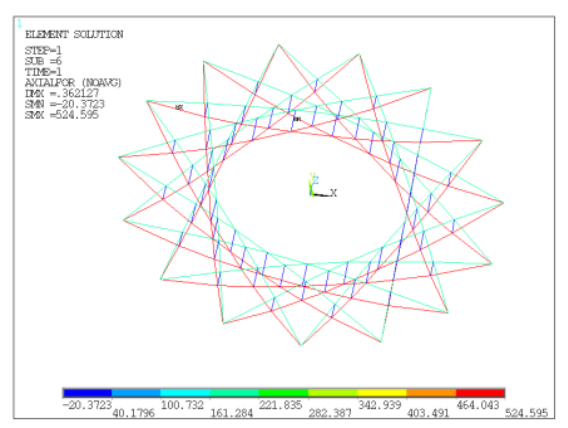

(a) Original scheme

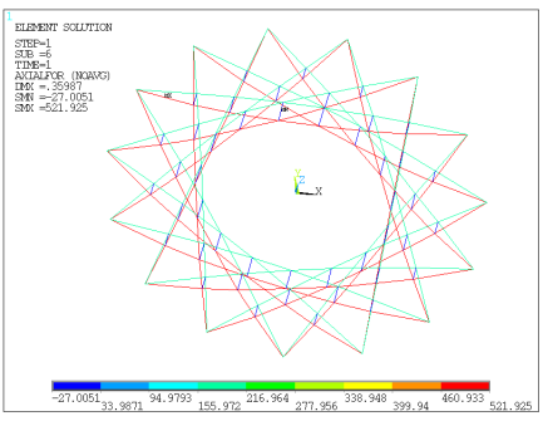

(b) Scheme 1

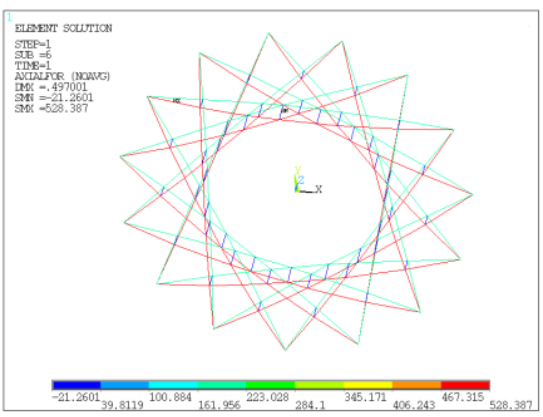

(c) Scheme 2

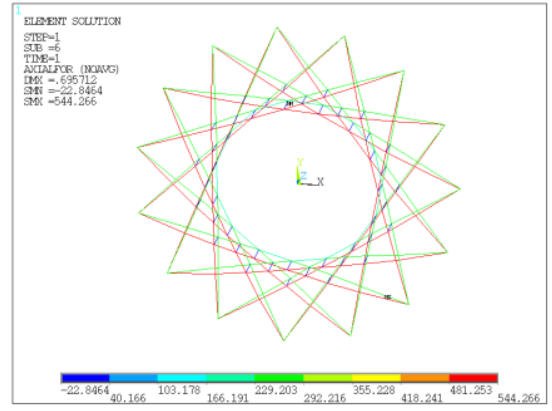

(d) Scheme 3

Fig. 20 Internal forces of original scheme and three jumped layout schemes

Table 4

Comparison results of structural responses of original scheme and three jumped layout schemes

\begin{tabular}{ccccc}
\hline Type and position & $\begin{array}{c}\text { Original } \\
\text { scheme }\end{array}$ & Scheme 1 & Scheme 2 & Scheme 3 \\
\hline Max. force of cable/kN & 524.59 & 521.9 & 528.39 & 544.25 \\
Position & XS5 & XS5 & XS5 & XS5 \\
Min. force of cable/kN & 195.50 & 198.63 & 207.98 & 228.58 \\
Position & SS1 & SS1 & SS1 & SS1 \\
Max. force of strut/kN & -10.67 & -14.52 & -19.09 & -13.94 \\
Position & Inner ring 2 & Virtual & Virtual & Virtual \\
ring & & ring & ring \\
Min. force of cable/kN & -20.37 & -27.00 & -21.26 & -22.85 \\
Position & Virtual ring & Inner ring & Inner ring & Inner ring \\
Vertical & & 3 & 1 & 1 \\
displacement/m & -0.356 & -0.354 & -0.489 & -0.679 \\
Position & Inner ring & Inner ring & Inner ring & Inner ring \\
& 3 & 3 & 2 & 3 \\
\hline
\end{tabular}

5.1.3. The comparison of steel consumption

The steel consumption of original scheme and three jumped layout schemes is shown in Table 4.

Table 5

The steel consumption of the original scheme and three jumped layout schemes

\begin{tabular}{ccccc}
\hline Type & $\begin{array}{c}\text { Original } \\
\text { scheme }\end{array}$ & Scheme 1 & Scheme 2 & Scheme 3 \\
\hline $\begin{array}{c}\text { Steel consumption/t } \\
\begin{array}{c}\text { Saving steel } \\
\text { consumption/t }\end{array}\end{array}$ & 39.13 & 36.007 & 36.369 & 37.144 \\
Percent/\% & - & 3.123 & 2.761 & 1.986 \\
\hline
\end{tabular}

Note: Percent=saving steel consumption/total steel consumption

From Table 5, the total amount of steel used in scheme 1 3 is smaller than the original scheme, but the total amount of steel used in scheme 1 is the smallest, saving $8.0 \%$ compared with the original scheme. The total the amount of steel used in scheme 3 is the largest. Therefore, scheme 1 saves the most amount of steel.

\subsubsection{Comparison of buckling analysis}

Nonlinear buckling analysis of the original scheme and three jumped layout schemes is carried out using the nonlinear FEM [15]. The comparison results are shown in Table 6.

From Table 6, the buckling loads of the original scheme and three jumped layout schemes have little change with or without self-weight, so the influence of self-weight on the buckling loads of structure are limited, and the large the self-weight is, the smaller the buckling loads are. 
Table 6

Buckling loads of original scheme and three jumped layout schemes.

\begin{tabular}{ccccc}
\hline Type & $\begin{array}{c}\text { Original } \\
\text { scheme }\end{array}$ & $\begin{array}{c}\text { Scheme } \\
1\end{array}$ & $\begin{array}{c}\text { Scheme } \\
2\end{array}$ & $\begin{array}{c}\text { Scheme } \\
3\end{array}$ \\
\hline $\begin{array}{c}\text { Buckling load without } \\
\text { self-weight/kN }\end{array}$ & 4536 & 4536 & 4454 & 4446 \\
$\begin{array}{c}\text { Buckling load with self- } \\
\text { weight /kN }\end{array}$ & 4266 & 4428 & 4284 & 4158 \\
\hline
\end{tabular}

Not considering self-weight, the structural buckling loads decrease gradually from the original scheme to scheme 3, which shows that the structural stiffness decreases gradually, but the reduction degree is limited. Considering self-weight, the structural self-weight decreases continuously from the original scheme to scheme 3. In contrast, the structural buckling loads increase first and then decrease, which shows that reducing structural self-weight can compensate for reducing structural stiffness for schemes 1 and scheme 2 . In contrast, the reduction of structural self-weight cannot compensate for reducing structural stiffness for scheme 3. From the nonlinear buckling analysis, scheme 1 reduces structural self-weight and increases structural buckling capacity.

It can be known from Section 5.1, comparing scheme 1 with scheme 2 and scheme 3:

(1) The distribution of pre-stress in scheme 1 is close to that of the original scheme.

(2) The maximum internal force of cables and their position is unchanged compared with the original scheme, and the internal forces of struts have changed. The cross-sections of struts should be rechecked after jumped layout.

(3) Jumped layout reduces not only structural self-weight but also improves structural buckling capacity.

The optimal order of jumped layout of ACCTS: scheme $1>$ scheme $2>$ scheme 3, which is identical to the optimal order of planar cable-truss frame.

For the jumped layout of ACCTS, it is suggested that the struts close to the virtual inner ring should be removed first, and the integral or partial symmetrical jumped layout should be adopted to maintain the symmetry of the structure.

\subsection{The influences of jumped layout on the static performance of ACCTS}

It is known from Section 5.1 that scheme 1 is the optimal scheme of jumped layout, so study on static and dynamic performance based on scheme 1 .

It is known the equivalent nodal loads calculated in Section 5.1.2 are $\boldsymbol{F}$. The internal forces and nodal displacements of the structure under full span and half span loads of $0.7 F, 0.9 F, 1.1 F, 1.3 F, 1.5 F, 1.7 F$ are studied.

\subsubsection{Under full-span loads}

It can be seen from Fig. 21 that under full-span loads, the internal forces of upper chord cables decrease gradually, and the internal forces of lower chord cables increase gradually with the increase of loads, which is linearly related to loads. The internal forces of upper and lower chord cables in scheme 1, so the influence of jumped layout on cables' internal forces is minimal. From Fig. 21(c), it is known that after jumped layout of strut B3, the variations of internal forces of strut B2 and strut B4 close to strut B3 are dramatically more extensive than the internal force of strut B1. Meanwhile, it is known

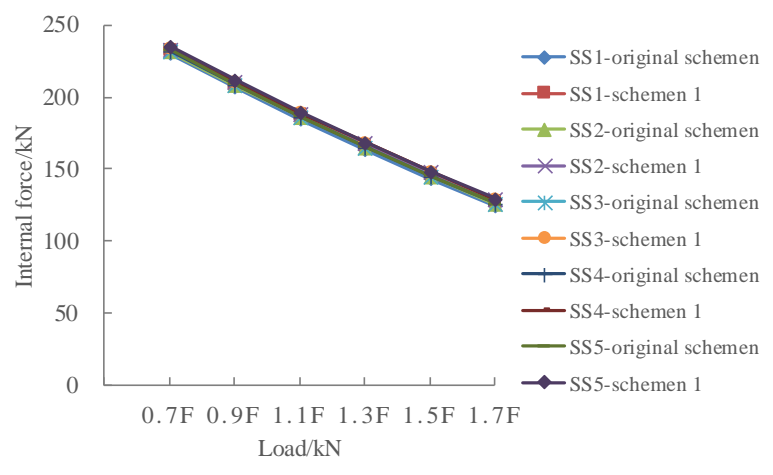

(a) Internal forces of upper cables

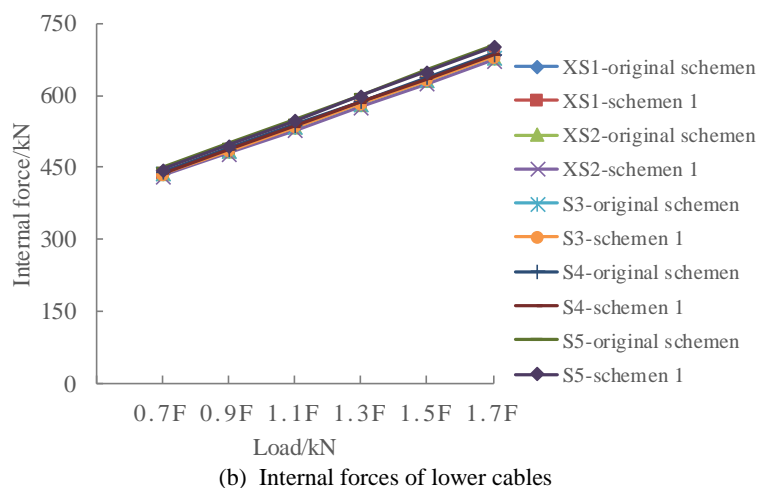

(b) Internal forces of lower cables $\mathrm{Load} / \mathrm{kN}$

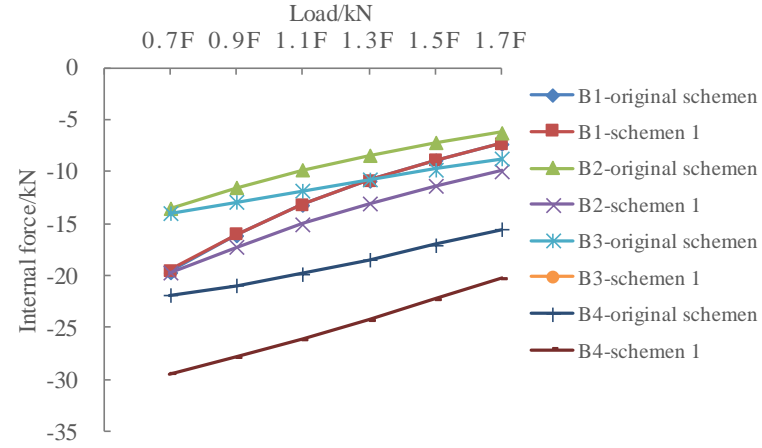

(c) Internal forces of struts

$\mathrm{load} / \mathrm{kN}$

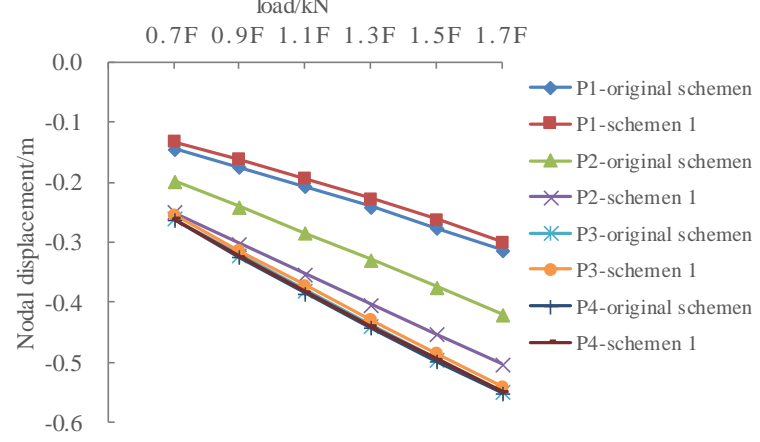

(d) Internal displacements of nodes

Fig. 21 Relation of internal force and nodal displacement of original scheme and scheme 1 under full-span loads

from Fig. 21(d) that the displacement of node P2 corresponding to the strut B2 has also changed significantly. Hence, the effect of jumped layout on struts' mechanical performance is greater than that of cables.

\subsubsection{Under half-span loads}

The computational results under half-span loads are shown in Fig. 22.

It is known from Fig. 22 that the change laws of internal forces and nodal displacements for all components are the same under half-span loads and fullspan loads. The influence of jumped layout on the internal forces of cables is minimal; forces of struts are more extensive, so the influence of removed struts on struts' mechanical performance is excellent.

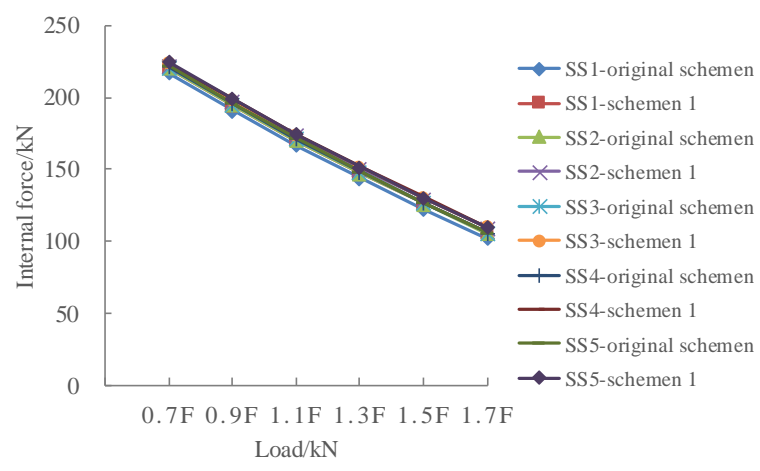

(a) Interanl forces of upper chord cables 


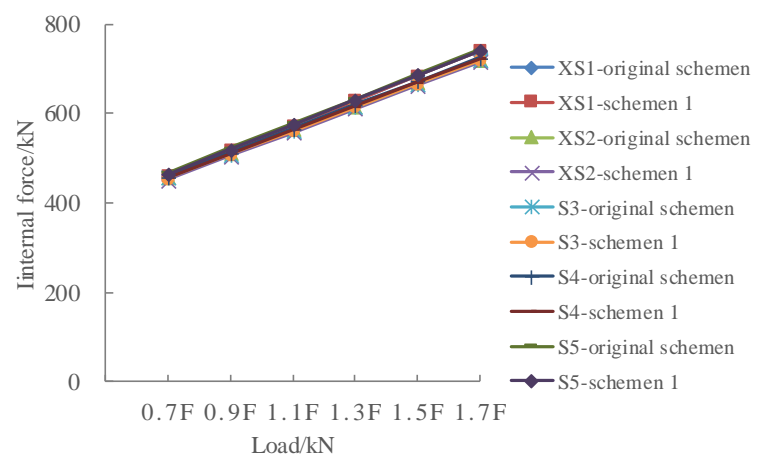

(b) Internal forces of lower chord cables

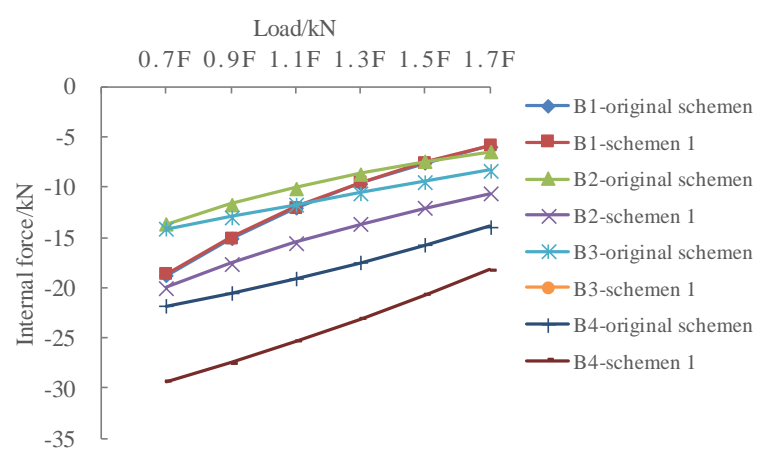

(c) Internal forces of struts

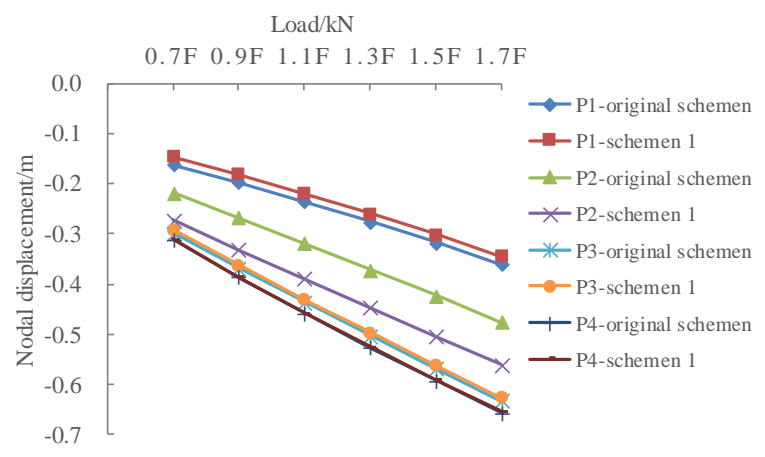

(d) The displacements of nodes

Fig. 22 Relation of internal force and nodal displacement of original scheme and scheme 1 under half-span loads performance is excellent.

5.2.3. The influence of jumped layout on the importance of structural components

From Sections 5.2.1 5.2.2, it is known that under full-span loads and halfspan loads, the change laws of the internal forces and nodal displacement of the original scheme and scheme 1 are identical. Although the displacement of the nodes at the jumped layout and the internal force of struts near it have changed, it can be seen from the numerical calculation results that when the external loads of the two schemes increases from $0.7 \boldsymbol{F}$ to $1.7 \boldsymbol{F}$, the mechanical characteristics of the structure remain unchanged. It shows that the static performances of structure do not change substantially after jumped layout, so structural components' importance does not change after jumped layout.

\subsection{The influence of jumped layout on the dynamic performance on ACCTS}

Natural vibration frequency, vibration mode, and damping ratio of the structure are three critical parameters that reflect dynamic load capacity and valuate dynamic structural features. It also includes the basis of structural wind spectrum analysis and seismic response spectrum analysis. ACCTS is a flexible structure, and large deformation and pre-stress effects are taken into account when carrying out mode analysis. In ANSYS software, pre-stress effects and large deformation are considered by setting stress stiffness and large deformation commands.

\subsubsection{Basic theory of model analysis}

Being similar to the general cable-net structures, when ACCTS has small amplitude vibration at the static equilibrium position, the un-damped motion equation of structure system according to the Hamiltonian Variation Principle can be described as:

$$
[M]\{\ddot{U}\}+[K]\{U\}=\{0\}
$$

$[\boldsymbol{M}]$ is the structure's mass matrix; $[\boldsymbol{K}]$ is the tangential stiffness matrix when the structure is in the current static equilibrium state.

Assuming that structure is in simple harmonic motion with frequency $\omega$, and which is substituted into the Eq.(1), the generalized feature equation of structure can be obtained as:

$$
\left([K]-\omega^{2}[M]\right)\{U\}=\{0\}
$$

Due to arbitrariness of displacements, Eq.(2) should satisfy:

$$
\left|[K]-\omega^{2}[M]\right|=\{0\}
$$

By solving Eq.(3), every order frequency of structure can be obtained. When the frequencies obtained are substituted into the Eq.(2), the vibration modes can be obtained. Block Lanczos Method (LANB) is used to solve Eq.(3). The method has the obvious advantages of fast calculation speed, few input parameters and high accuracy of results, and is especially suitable for large span spatial structure with symmetry.

\subsubsection{The comparison of vibration performance of original scheme and scheme} 1

Thought studying on the dynamic performance of original scheme and scheme 1, the first 6 order frequencies and modes are given, shown in Table 7 and Figs. 23 24.

\begin{tabular}{|c|c|c|c|}
\hline \multirow{2}{*}{ Order } & \multicolumn{2}{|c|}{ Frequency / HZ } & \multirow{2}{*}{$\begin{array}{c}\text { Vibration mode } \\
\text { Original scheme / scheme 1 }\end{array}$} \\
\hline & Original scheme & Scheme 1 & \\
\hline 1st order & 1.733 & 1.796 & Two-direction positive symmetric upper and lower vibration \\
\hline 2nd order & 1.733 & 1.796 & Two-direction positive symmetric upper and lower vibration \\
\hline 3 rd order & 2.049 & 2.157 & Integral upper and lower vibration \\
\hline 4 th order & 2.072 & 2.180 & Three-direction positive antisymmetric upper and lower vibration \\
\hline 5 th order & 2.072 & 2.180 & Three-direction positive antisymmetric upper and lower vibration \\
\hline 6 th order & 2.114 & 2.251 & Integral antisymmetric upper and lower vibration \\
\hline 7 th order & 2.114 & 2.251 & Integral antisymmetric upper and lower vibration \\
\hline
\end{tabular}

Table 7

First 6 order frequencies of original scheme and scheme 1 


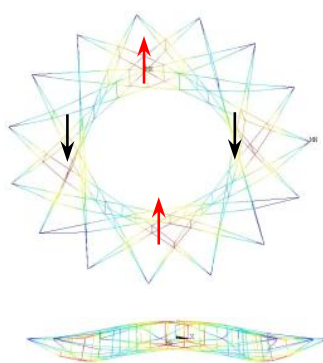

1st Mode

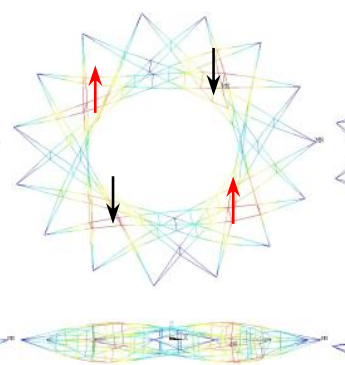

2nd Mode

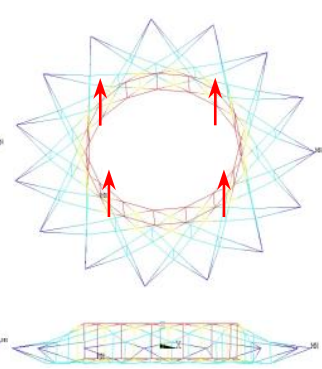

3rd Mode
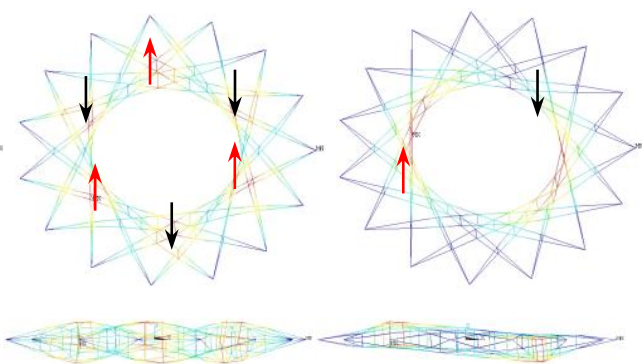

4th Mode

6th Mode

Fig. 23 First 6 vibration modes of original scheme (scale factor=10)

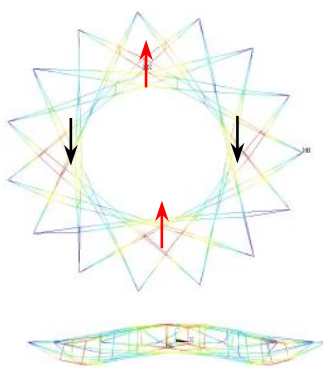

1st Mode

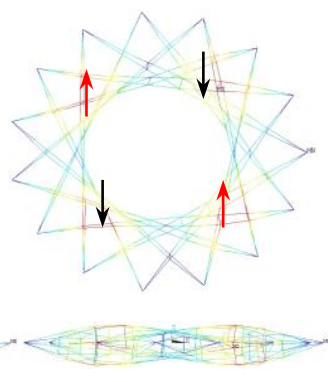

2nd Mode
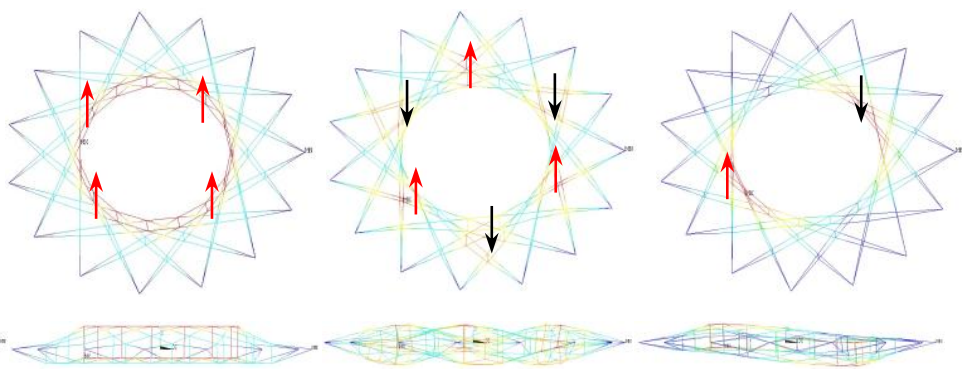

3rd Mode

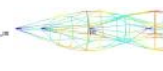

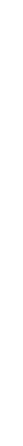

Fig. 24 First 6 order vibration modes of scheme 1 (scale factor=10)

Table 7 and Figs. 23 24 show that the natural vibration frequencies of the original scheme and scheme 1 are densely distributed and slightly different. In contrast, the first seven order modes of the two schemes are identical. The 1st and 2 nd modes of the original scheme and scheme 1 are two-direction positive symmetric upper and lower vibration (about XY axis symmetrical vibration). The difference between the 1st and 2nd modes is that an angle is changed based on the 1st mode (caused by multiple symmetrical axes of structure). The first three order modes of the two schemes are all integrally upper and lower vibration. The 4th and 5th order modes of the two schemes are all three-direction antisymmetric upper and lower vibrations (only give the 4 th order mode). The difference between the 5 th and 4 th order modes is that they also change an angle based on the 4th order modes. The 6 th and 7 th order modes of the two schemes are all integrally asymmetric (only the 6th is given). The difference between the 7 th-order and 6th-order modes is that they change an angle based on the 6th order mode.

Meanwhile, it can be seen from 1st to seventh order modes that the structural vibration is accompanied by local torsion of different degrees of the planar cabletruss frame. By observing the first ten modes, the vibration modes of ACCTS can be divided into the leading cable system structure's coupled vibration in the horizontal plane. The upper and lower vibration of the leading cable system structure in the vertical plane was accompanied by the planar cable-truss frame's local torsion.

Continuing to observe the first 100 order frequencies of original scheme and scheme 1, shown in Fig. 25.

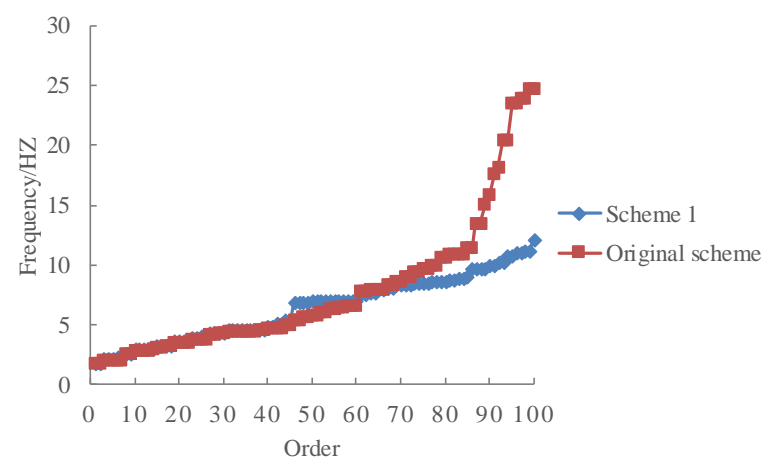

Fig. 25 Trend diagram of first 100 order frequencies of the original scheme and scheme 1

It can be seen from Fig. 25 that the trend of the first 45 order frequencies of the original scheme and scheme 1 is similar, and there is a difference between the original scheme and scheme 1 after the 46th order frequency. After the 46th order frequency, the frequencies of scheme 1 increase steadily and continually with the order. However, the original scheme's frequencies increased by leaps and bounds, and the frequencies of occurrence are higher, especially after the 80 th order frequency.

For the rigid structure, the 1st order vibration model is an integral torsional model, which is generally bad for structure seismic, and it should be avoided as far as possible [16]. For ACCTS, the 1st order model shape is up and down vibration and out-of-plane local rotation of plane cable-truss, which is not bad for the integral structure, consistent with the planar results cable-truss frame.

\section{Conclusion}

Through the studies of planar cable-truss frame and ACCTS, the conclusions are as follows:

(1) When upper chord cables are slack, the initial stiffness equation and the critical slack load equation of the 2-bar and 6-cable planar cable-truss frame model were deduced. The theoretical values are identical to FEM values, which verifies the correctness of the theoretical equation.

(2) Based on ANSYS software, the influence of the position of middle struts on the cable-truss frame is studied when the middle struts are fixed or not. When the number of struts is more than a specific range, increasing struts does not improve the structural stiffness. It suggests that the number of struts should be about 6 8.

(3) According to the research results, the impact of jumped layout on the cabletruss frame's internal forces is small. However, it dramatically influences the internal forces of struts near jumped layout. The optimal order of jumped layout: strut 2-3>strut 4-5>strut 6-7.

(4) After the jumped layout, the self-weight of ACCTS is reduced, improves the structure's buckling capacity, and decreases the construction difficulty. The optimal order of jumped layout: scheme $1>$ scheme $2>$ scheme 3 , which is similar to the planar cable-truss frame's optimal order.

(5) From the static analysis results, the influence of jumped layout on cable forces is minimal, but it dramatically influences the internal forces of struts near jumped layout. The static performance of both the original scheme and scheme 1 is similar.

(6) For ACCTS, the 1st order model is upper and lower vibration accompanied out-of-plane local rotation of plane cable-truss frame, which is not bad for the integral structure, consistent with the results gained from the planar cable-truss frame. 


\section{Acknowledgments}

The authors would like to acknowledge the financial support of the National Natural Science Foundation of China (51778017), the financial support of the National Natural Science Foundation of China (51878014), the Natural Science Foundation of Beijing Municipality (8172011).

\section{References}

[1] Guo J M, Jiang J Q. An algorithm for calculating the feasible pre-stress of cable-struts structure. Engineering Structure, 2016, 118(1), 228-39.

[2] Chen L M, Hu D, Gao W F, Dong S L, Zhou Y Y, Zhang F B. (2018). Support node construction error analysis of a cable-strut tensile structure based on the reliability. Advances in Structural Engineering, 2008, 21(10), 1553-1516.

[3] Zhang A L, Sun C, Jiang Z Q. Experimental study on the construction shape-forming process and static behavior of a double strut cable dome. Journal of Zhejiang University-Science (Applied Physics and Engineering), 2018, 19(03), 225-239.

[4] Ge J Q, Zhang A L, Liu X G, Zhang G J, Ye X B, Wang S, Liu X C. Analysis of tension formfinding and whole loading process simulation of cable dome structure. Journal of building structures, 2012, 33(4):1-11.

[5] Deng H, Zhang M R, Liu H C, Dong S L, Zhang Z H, Chen L Q. (2016). Numerical analysis of the pretension deviations of novel Crescent-shaped tensile canopy structural system, Engineering Structures, 2016, 119, 24-33.

[6] Liu R J, Li X Y, Xue S D. Experimental and numerical research on Annular Crossed CableTruss Structure under cable rupture, Earthquake Engineering and Engineering Vibration, 2017, 16(3), 557-569.

[7] Xue S D, Liu R J, Li X Y. Concept proposal and feasibility verification of the annular crossed cable-truss structure, International Journal of Steel Structures, 2017, 17(4), 1549-60.

[8] Lu J, Xue S D, Li X Y, Liu R J. Study on membrane roof schemes of annular crossed cabletruss structure[J]. International Journal of Space Structures, 2019, 34(3-4):85-96.

[9] Jeon B, Lee J. Cable membrane roof structure with oval opening of stadium for 2002 FIFA world Cup in Busan. In: Proceedings of sixth Asian-Pacific conference on shell and spatial structures, 2000, 2, 1037-42.

[10] Liu R J, Xue S D, Li X Y. Static behavior analysis for annular crossed cable-truss structures. Spatial Structure, 2004, 20(01), 89-96.

[11] Liu R J, Xue S D, Li X Y. Preventing disproportionate displacements in an annular crossed cable-truss structure, International Journal of Space Structures, 2007, 32(1), 3-10.

[12] Xue S, Lu J, Li X, et al. Method of shape determination and solving self-stress mode of cabletruss tensioned structure based on constraints move method[J]. Advanced Engineering Sciences , 2020,52(2):1-8.

[13] Technical Specification for Cable Structure, JGJ257-2012 [S]. Beijing: China Architecture \& Building Press, 2008.

[14] Shen S D,Xu C B, Zhao C, W Y. Suspension structure design. Beijing:China Architecture \& Building Press, 2006.

[15] Liang X T, Yuan X F. Perfermance analysis of buckling in compressive strut supported by prestressed cables. Journal of Zhejiang University (Engineering Science), 2016, 29(03), $505-510$.

[16] Guo Y L, Tian G Y. Cable structure system, design theory and construction control. Beijing: Science Press, 2014. 